\title{
Agricultural growth and production variability of principal crops in India: an empirical investigation
}

\begin{abstract}
In the post-Independence era, the Indian agricultural sector presents a curious paradox. The sector has witnessed some early breakthroughs in form of Green Revolution (GR) particularly heart-warming has been the growth in the food grain production enabling the nation to put an end to the frequent occurrence of famines marking the history of Indian economy until the middle of this century. In this context, we can say that the Green Revolution Technology (GRT) may not have reduced the instability of agriculture during the last 2 decades. Regional disparities and instabilities in agriculture have remained the subject of deep concern in India. Year-to-year fluctuations in output and variations in productivity across space raises the risk involved in farm production and considerably affects farmer's decision to adopt high paying technologies and also affects price stability hence increases vulnerability of low income households to market. Except jowar, bajra, maize, groundnut, tobacco, sugarcane, jute \& Mesta and coarse cereals, the growth rate of output has increased significantly in the $1^{\text {st }}$ and $2^{\text {nd }}$ phase of GR. A moderate and significant growth in production accompanied by a low level of instability of any crop is desirable for sustainable development of agriculture in India as compared to high growth in production and high level of instability. There is an inevitable trend that arable land in India will decline over time due to urban development and industrialization.
\end{abstract}

Keywords: agriculture growth, production variability, weather uncertainty, regional disparity
Volume 8 Issue I - 2018

\begin{abstract}
Asis Kumar Senapati,' Phanindra Goyari²
'Department of Economics, Ravenshaw University, India

${ }^{2} S$ chool of Economics, University of Hyderabad and Visiting

Fellow@Texas Christian University, USA
\end{abstract}

Correspondence: Asis Kumar Senapati,Assistant Professor, Department of Economics, Ravenshaw University, India, Email asiseco@gmail.com

Received: October 13, 2016 | Published: February 07, 2018

\section{JEL classification}

\section{Q18; Q10; C5}

\section{Introduction}

Historically, agriculture has been the mainstay of Indian economy providing bread and butter to the farming society. We often described Indian agriculture as a gamble in monsoons i.e. susceptible to weather variations and climate change. Even if we have moved quite a distance away from the situation of yesteryears, still the agricultural profession is tantamount to gambling with nature. Agriculture which is providing more than $70 \%$ of livelihood to the rural people must not be neglected Cummings et al., ${ }^{1}$ Boyce. ${ }^{2}$ Hence, it is imperative that agricultural production keeps pace with our alarming population growth and for increased incomes. Sustained growth in agricultural production and productivity is essential for overall stability of the Indian economy. The main concern in the strategy for agricultural development in India has been "Growth with Stability" from fourth five year plan onwards so that a steady rise in agricultural production should be supported by a policy of stabilization of agricultural prices Das; ${ }^{3}$ Despande et al. ${ }^{4}$ India now has achieved high growth rates of agricultural production from mid-1960s through till now by using high-yielding varieties, improved agronomic practices, plant protection measures, chemicals, fertilizers and mechanization what popularly known as "Green Revolution Technology" (GRT).

It succeeded in transforming India from a large food importer and large recipient of food aid in the 1950s and 1960s, to a food secure country that could occasionally export food in the 1980s and 1990s Anderson et al. ${ }^{5}$ There has been a distinct slowdown in agricultural growth since the mid-1990s which has adversely impacted the livelihood base of the farming community. The slowdown has occurred in all the sub-sectors of agriculture which were the main drivers of the agricultural growth in the immediate past. A large number of proximate and structural factors have contributed to the declining share of agriculture to the GDP. The institutional retardation has begun to happen when the farming community lost its capacity to generate self-equilibrating response to macro-economic changes. The liberalization of agricultural trade has exposed the Indian commercial agriculture to the volatility in the world commodity markets Ray et al. ${ }^{6}$ The uncertainties associated with Indian Agriculture in general are attributed to natural phenomena such as failures of monsoon, flood, cyclone or drought.

The overemphasis on the natural factors by politicians, bureaucracy and agricultural experts for whatever has been happening in the agriculture sector has made it all most impossible to know the real impacts of developmental action on the sector. The technological interventions made in the agricultural sector as a part of the development paradigm the Indian state adopted after independence and which gathered momentum in the 1960 s, with the introduction of the Green Revolution technologies aiming for quick-growing and high-yielding agricultural crops. The issue of sustaining agriculture on a self-reliant manner was overlooked and making the country self reliant in food production took the priority of the planners (Vasundhara, 2005). In the post-Independence era, the Indian agricultural sector presents a curious paradox. The sector has witnessed some early breakthroughs in form of GR particularly heart-warming has been the growth in the food grain production enabling the nation to put an end to the frequent occurrence of famines marking the history of Indian economy until the middle of this century. In this context, we can say that the GRT may not have reduced the instability of agriculture 
during the last 2 decades. Regional disparities and instabilities in agriculture have remained the subject of deep concern in India. Yearto-year fluctuations in output and variations in productivity across space raises the risk involved in farm production and considerably affects farmer's decision to adopt high paying technologies and also affects price stability hence increases vulnerability of low income households to market Rao et $\mathrm{al}^{7}{ }^{7}$ No doubt, it has attracted special interest in India towards attainment of self-sufficiency in food grains production invoked large number of researchers to see and verify its impact on agricultural growth which has not been so clear and has always remained an exciting area to explore. In the next section, we will discuss studies that focused so far on this issue nationally as well as internationally.

\section{Existing literature on growth and instability}

Anderson et al., ${ }^{5}$ claimed that the GRT succeeded in transforming India from a large food importer and large recipient of food aid in the 1950 s and 1960 s, to a food secure country that could occasionally export food in the 1980s and 1990s. Brush ${ }^{8}$ argued that technology diffusion between different geographic and cultural regions has greatly increased with the advent of mass communication, rural development programs and agricultural research. Biological uniformity has resulted from the widespread adoption of high-yielding crop varieties (HYVs). Greater connectedness has accompanied the incorporation of local production systems into regional networks of input supplies and commodity markets. With these predictions, we will now show studies that focused on this crucial issue. Here, an attempt is made to provide a clear cut ideas related to growth, instability and production variability in agriculture. This review is intended to trace out the existing inconsistencies or research gap so as to fetch requisite hypothesis or the research questions for the present study.

We have highlighted studies that have focused on the issues of growth and instability in agriculture, particularly based on regional disparity, production variability, and climate variability and also raised some methodological issues therein. Several studies on the food grain situation in India have pointed out that GR has contributed to the growth in production and productivity. Some researchers concluded that through wide spread adoption of a modern input packages with improved seed varieties, fertilizers, irrigation methods, and improved production practices would reduce the classic instability of subsistence agriculture caused by weather, pests, and diseases infestation Hazell. ${ }^{9}$ At the same time others argued that much of the alarming instability is due to the widespread adoption of modern technologies Mehra; ${ }^{10}$ Ray $\left.^{6}\right)$. Ray et al., ${ }^{6}$ emphasized the role of weather in agricultural production and raised the issue like how climatic factors enter the production of a crop of a region and whether people can influence it through technological advances or not. Moreover, it has institutional dimensions depending upon institutional response of the purposed state Nadkarni et al. ${ }^{4}$ Boyce ${ }^{2}$ explored the issue and analyzed agricultural performance of West Bengal with respect to demographic, technological and institutional change. Rao et al., ${ }^{7}$ identified sensitivity of crop output with respect to rainfall and erratic irrigation facility are the most important factors responsible for unstable agriculture. In the context of variability of agricultural production due to certain weather induced variables as well as manmade disasters, agrarian distress, alarming crisis of recent years and the emergency of providing necessary risk management techniques as well as looking into the plight of the farmers the proposed study made an attempt to examine the growth, instability of major crops in India. The present study is based on the hypothesis that instability/ variability of various crops augmented during Post-Green Revolution (PGR) phase in India and there has been negative association between instability and growth of crop production.

\section{Data and methodology}

The present study has used time series data on area, production and yield at national level and district levels for principal crops. The data were culled from directorate of economics and statistics, department of agriculture and co-operation, govt. of India for the national level data and also CMIE data various issues. Evaluation of agricultural growth performance and instability attempted in this study has been divided into three distinct phases namely, period-1, i.e. pre-green revolution period comprising from 1950-51 to 1964-65, period-2, i.e. the early phase of green revolution period covering from 1965-66 to $1987-88$ and period-3, i.e. post-green revolution period (widespread diffusion and maturing of technology adoption) covering from 198889 to $2010-11$.

An alternative measure of changes in growth rates over time can be derived from comparisons of estimated growth rates in different sub-periods. If we will fit exponential growth rates in sub-periods of a time series independently, the resulting trend lines are likely to be discontinuous. It will lead to anomalies such as sub-period growth rates which can exceed or are less than the estimated exponential growth rate for the period as a whole. Kinked exponential models (K-E) are models which make use of information regarding the values of the variable in question throughout the time series in estimating the growth rate for a given sub-period. The rationale for preferring fitted trends over simple points-to-point growth rate calculations is that OLS estimates are less affected by instability or cyclical fluctuations. This eliminates what can be termed the discontinuity bias of conventional sub-period growth rate estimates. K-E models impose linear restrictions so as to eliminate the discontinuity between sub-periods provides a superior basis for comparisons of sub-period growth rate.

The generalized K-E model for m sub-periods and m-1 kinks, let the kink points be $\mathrm{K}_{1}, \ldots \mathrm{k}_{\mathrm{m}-1}$, and the sub-period dummy variables as $D_{1}, D_{m}$ then the unrestricted model for joint estimation of the subperiod with no continuity requirement is :

$$
\text { Ln } Q_{t}=a_{1} D_{1}+a_{2} D_{2}+\ldots+a_{m} D_{m}+\left(b_{1} D_{1}+b_{2} D_{2}+\ldots+b_{m} D_{m}\right) t+u_{t}
$$

Applying the appropriate m-1 linear restriction,

$$
a_{i}+b_{i} k_{i}=a_{i+1}+b_{i+1} k_{i,} \text { for all } i=1, \ldots, m-1
$$

we obtain the generalized K-E model.

$$
\ln Q_{t}=a_{1}+b_{1}\left(D_{1} t+\sum_{(j=2)}^{m} D_{j} K_{1}\right)+b_{2}\left(D_{2} t-\sum_{(j=2)}^{m} D_{j} K_{1}+\sum_{(j=3)}^{m} D_{j} K_{2}\right)+\ldots . .+b_{i}\left(D_{i} t-\sum_{(j=i)}^{m} D_{j} K_{(i-1)}+\sum_{(j=i+1)}^{m} D_{j} K_{i}\right)+\ldots . .+b_{m}\left(D_{m} t-D_{m} k_{m-1}\right)+u_{t}
$$

To measure the growth rates in different sub-periods the following kinked exponential model is used:

$$
\ln Q_{t}=a_{1}+b_{1}\left(D_{1} t+D_{2} k_{1}+D_{3} k_{1}\right)+b_{2}\left(D_{2} t-D_{2} k_{1}-D_{3} k_{1}+D_{3} k_{2}\right)+b_{3}\left(D_{3} t-D_{3} k_{2}\right)+u_{t}
$$


In this equation, the growth rates for the three sub-periods are given by the OLS estimates of the coefficients $b_{1}, b_{2}$, and $b_{3}$ respectively. Estimating the trend break equation also tests the significance of the difference between the growth rates in two different sub-periods:

$$
\ln Q_{t}=a_{1}+b_{1} t+b_{1}^{*}\left(D_{2} t-D_{2} k_{1}-D_{3} k_{1}+D_{3} t\right)+b_{2}^{*}\left(D_{3} t-D_{3} k_{2}\right)+u_{t}
$$

Where, $b_{1}{ }^{*}$ and $b_{2}{ }^{*}$ are the difference between the first and second sub-period growth rates and the difference between the third and second sub-period respectively. There are number of techniques available to measure the index of instability. In the present study, the instability in area, production and yield of principal crops is measured in relative terms by the Cuddy-Della Valley index which is used in recent years as a measure of instability in time series data. The simple co-efficient of variation overestimates the level of instability in time series data characterized by long trends whereas the Cuddy-Della Valley index Cuddy et al., ${ }^{11}$ corrects the coefficient of variation.

The instability index IX is:

$$
I X=C V \sqrt{\left(1-R^{2}\right)}
$$

Where, CV is coefficient of variation in percentage form, $\mathrm{R}^{2}$ is coefficient of determination from a time trend regression adjusted by the number of degrees of freedom. To analyze the contributions of area, yield and their interaction effects on the variability of total production, the decomposition of production variability is essential to know the most important factors contributing it. We have used the following decomposition method Ghosh. ${ }^{12}$

$$
\text { As we know, } Y=\frac{P}{A}
$$

\begin{tabular}{|c|c|c|c|c|c|c|}
\hline \multicolumn{4}{|c|}{ Kinked exponential growth rates } & \multicolumn{3}{|l|}{ Trend breaks } \\
\hline Crops & $\begin{array}{l}1950-51 \text { to } 1964- \\
65\end{array}$ & $\begin{array}{l}1965-66 \text { to } 1987- \\
88\end{array}$ & $\begin{array}{l}1988-89 \text { to } \\
2010-11\end{array}$ & First break & Second break & $\mathbf{R}^{2}$ \\
\hline Rice & $2.72(|0.4|)^{*}$ & $2.79(23.59)^{*}$ & $1.85(\mid 2.87)^{*}$ & $0.06(0.18)$ & $-0.94(-4.01)^{*}$ & 0.98 \\
\hline Wheat & $4.89(10.44)^{*}$ & $6.22(29.36)^{*}$ & $1.33(5.18)^{*}$ & $1.32(2.14)^{* *}$ & $-4.88(-1.61)^{*}$ & 0.98 \\
\hline Jowar & $\mathrm{I} .43(3.82)^{*}$ & $1.12(6.60)^{*}$ & $-2.78(-13.53)^{*}$ & $-0.32(-0.64)$ & $-3.9 \mid(-11.59)^{*}$ & 0.8 \\
\hline Bajra & $3.08(5.76)^{*}$ & $1.01(4.15)^{*}$ & $2.03(6.93)^{*}$ & $-2.07(-2.94)^{*}$ & $1.03(2.14)^{* *}$ & 0.86 \\
\hline Maize & $5.85(22.31)^{*}$ & $\mathrm{I} .63(13.77)^{*}$ & $3.89(27.03) *$ & $-4.22(-12.19)^{*}$ & $2.25(9.58)^{*}$ & 0.98 \\
\hline Gram & $0.29(0.56)$ & $-0.49(-2.1 \mathrm{I}) * *$ & I.I4(3.98)* & $-0.79(-1.15)$ & $\mathrm{I} .63(3.50)^{*}$ & 0.22 \\
\hline Groundnut & $2.55(5.62)^{*}$ & $1.47(7.20)^{*}$ & $-0.13(-0.51)$ & $-1.07(-1.79)^{* * *}$ & $-1.61(-3.94)^{*}$ & 0.83 \\
\hline $\begin{array}{l}\text { Rapeseed \& } \\
\text { Mustard }\end{array}$ & $2.18(2.73)^{*}$ & $4.96(|3.7|)^{*}$ & $2.64(6.01)^{*}$ & $2.77(2.62)^{*}$ & $-2.32(-3.23)^{*}$ & 0.94 \\
\hline Cotton & $2.82(4.57)^{*}$ & I.74(6.25)* & $4.34(I 2.83)^{*}$ & $-1.07(-1.32)^{* * * *}$ & $2.59(4.69)^{*}$ & 0.93 \\
\hline Tobacco & $2.3 \mathrm{I}(5.09)^{*}$ & $1.95(9.48)^{*}$ & $-0.03(-0.11)$ & $-0.36(-0.61)$ & $-1.97(-4.84)^{*}$ & 0.87 \\
\hline Sugarcane & $5.6(14.86)^{*}$ & $2.84(16.72)^{*}$ & $2.11(10.21)^{*}$ & $-2.75(-5.54)^{*}$ & $-0.73(-2.17)^{* *}$ & 0.97 \\
\hline Jute \& Mesta & $2.54(4.81)^{*}$ & $1.22(5.10)^{*}$ & I.I6(4.0I)* & $-1.33(-1.90)^{* * *}$ & $-0.06(-0.12)$ & 0.83 \\
\hline TUR(ARHAR) & $-1.24(-4.61)^{*}$ & $1.86(15.33)^{*}$ & $0.19(1.29)$ & $3.11(8.75)^{*}$ & $-1.67(-6.93)^{*}$ & 0.9 \\
\hline Total Food grains & $2.42(10.36)^{*}$ & $2.88(27.30)^{*}$ & $1.49(11.70)^{*}$ & $0.46(1.49)^{* * * *}$ & $-1.38(-6.59)^{*}$ & 0.98 \\
\hline Coarse Cereals & $2.16(8.69)^{*}$ & $0.73(6.48)^{*}$ & $0.69(5.10)^{*}$ & $-1.43(-4.36)^{*}$ & $-0.03(-0.14)$ & 0.91 \\
\hline Total Pulses & $0.3(0.87)$ & $0.56(3.65)^{*}$ & $0.52(2.74)^{*}$ & $0.26(0.59)$ & $-0.05(-0.16)$ & 0.61 \\
\hline Total Oilseeds & $1.67(2.84)^{*}$ & $3.32(12.45)^{*}$ & $2.82(8.70)^{*}$ & $1.65(2.11)^{* *}$ & $-0.5 \mathrm{I}(-0.94)$ & 0.94 \\
\hline
\end{tabular}

Table I Growth rates of production of crops in India during |950-5 I to 2010-II

Note: Authors calculation based on Department of Agriculture and Cooperation (DAC) govt. of India data. Standard errors are in parentheses. *, ** and $* * *$ implies significant at $1 \%, 5 \%$ and $10 \%$ level of significance, respectively.

$$
\begin{aligned}
& \text { » } \log \mathrm{Y}=\log \mathrm{P}-\log \mathrm{A} \\
& \text { » } \log \mathrm{P}=\log \mathrm{A}+\log \mathrm{Y}
\end{aligned}
$$

Where, $\mathrm{Y}=$ Yield; $\mathrm{P}=$ Production and $\mathrm{A}=$ Area respectively.

In other words,

Production variability $=$ Area effect + yield effect + their interaction effect.

Finally, to find out the possible nexus between instability and growth, we have used simple correlation and regression estimation for the data.

\section{Agricultural growth in India}

In this section issues relating to the growth rate of production of principal crops in India were analyzed. ${ }^{13}$ The sub-period growth rates are estimated by means of the Kinked exponential model, i.e., without discontinuities at the break point. The break allows for a change in growth rates with the advent of the High Yield Varieties (HYVs) in the mid-1960s and diffusion of widespread technology in the 1990s. Table 1 presents the growth rate of crop output in India. Except jowar, bajra, maize, groundnut, tobacco, sugarcane, jute \& mesta and coarse cereals, the growth rate of output has increased significantly in the $1^{\text {st }}$ and $2^{\text {nd }}$ phase of green revolution. The growth rate of jowar, groundnut and tobacco declined significantly in the $2^{\text {nd }}$ phase of green revolution implying the lesser impact of technology diffusion on these crops while the technology adoption helps the increase in growth of remaining crops such as rice, wheat, Rapeseed \& Mustard, Tur (Arhar), total food grains, total pulses and total oilseeds (Table 1). 


\section{Instability in Indian agriculture}

Tremendous efforts have been made since independence to raise the efficiency and productivity of Indian agricultural sector. Adoption of GRT helped India in achieving a substantial increase in food production and succeeded in transforming India from a large food importer and large recipient of food aid in the 1950s and 1960s, to a food secure country that could occasionally export food in the 1980s and 1990s Anderson et al. ${ }^{5}$ However, the technology mayn't have reduced the instability of agriculture during last two decades. Some studies concluded that the widespread diffusion of technology would reduce the classic instability of subsistence agriculture caused by weather, pests, and diseases while others argued that much of the increased instability in food grains production is due to the widespread diffusion of technology. However, its impact on agriculture food production has not been quite clear and has remained a great area to explore. Table 2 presents the instability in area, production and yield of major crops in India. Fluctuations in area for all crops rose in the subsequent phases of GR except bajra and sugarcane. Similarly, variability in production is high in the subsequent phases of GR except gram and total pulses, where variability is less as compared to pre-GR period. The same story is in case of yield variability where variability of all crops rose significantly in the subsequent phases except crop such as Tur (Arhar). So we can conclude that green revolution technology augmented the variability of area, production, and yield of major crops except few crops. The decomposition of production variability into its different components is done here for all crops for 3 sub-periods and the results are shown in Tables 3-5. The major findings of the production variability decomposition are outlined as follows.

During $1^{\text {st }}$ sub-period, the contribution of yield variability is more in case of rice, jowar, bajra, tur, and cereals whereas the contribution of interaction effect between area and yield is significant in case of maize, sugarcane, tobacco, and cotton. Area variability has been seen as other determinant for the remaining crops. During the $2^{\text {nd }}$ subperiod, except tur, wheat, rapeseed \& mustard, sugarcane and total oilseeds, the contribution of yield variability is highly significant for the rest of the crops whereas, in case of tur, area variability is more and for other 4 crops the interaction between area and yield is significant. During the $3^{\text {rd }}$ sub-period, the contribution of area variability has been seen in case of jowar, tobacco and sugarcane whereas; interaction effect is more in case of wheat, maize, gram, and total oilseeds. For the remaining crops, the contribution of yield effect is significant in explaining output variability.

Here it can be concluded that except few crops, the contribution of yield variability is significant in determining output variability in all the sub-periods. The contribution of interaction effect between area and yield, and the contribution of extension of area were next to the yield effect for most of the crops in India. A moderate growth in production and yield accompanied by low level of instability for any crop is desired for sustainable development of agriculture as compared to high growth in production and yield along with high level of instability. ${ }^{14-21}$

Table 2 Instability in area, production and yield of major crops in India during 1950-5 I to 20 I0-1 I

\begin{tabular}{|c|c|c|c|c|c|c|c|c|c|}
\hline \multirow{2}{*}{ Crops } & \multicolumn{3}{|c|}{ Period-I (1950-5 I to I964-65) } & \multicolumn{3}{|c|}{ Period-II (1965-66 to 1987-88) } & \multicolumn{3}{|c|}{ Period-III (1988-89 to 20 I0-II) } \\
\hline & Area & Production & Yield & Area & Production & Yield & Area & Production & Yield \\
\hline Rice & 0.65 & 3.15 & 3.27 & 1.28 & 4 & 3.5 & 2.4 & 3.67 & 2.03 \\
\hline Wheat & 4.63 & 5.32 & 4.3 & 5.34 & 5 & 4.3 & 7.8 & 9.37 & 8.36 \\
\hline Jowar & 1.96 & 5.55 & 4.49 & 3.33 & 9 & 8.5 & 4.1 & 6.26 & 7.02 \\
\hline Bajra & 3.75 & 7.57 & 5.37 & 3.07 & 13 & 11 & 3.2 & 8.61 & 6.29 \\
\hline Maize & 1.94 & 4.82 & 3.46 & 3.97 & 6 & 5.7 & 3.9 & 7.38 & 3.16 \\
\hline Gram & 8.19 & 12.69 & 5.7 & 3.53 & 8 & 6.1 & 9.5 & 10.7 & 7.34 \\
\hline Groundnut & 2.43 & 5.01 & 4.36 & 1.93 & 6 & 5.1 & 3.9 & 8.15 & 6.4 \\
\hline Rapeseed \& Mustard & 3.9 & 6.14 & 3.9 & 3.87 & 13 & 10 & 14 & 15 & 8.76 \\
\hline Cotton & 4.95 & 5.44 & 3.35 & 3.74 & 5 & 3.5 & 5.8 & 23.4 & 20.16 \\
\hline Tobacco & 3.02 & 3.33 & 2.4 & 6.57 & 8 & 3.1 & 16 & 16.1 & 15.47 \\
\hline Sugarcane & 5.04 & 7.08 & 3.27 & 4.41 & 5 & 2.4 & 4.7 & 7.38 & 3.78 \\
\hline Jute \& Mesta & 6.11 & 6.36 & 2.38 & 7.53 & 9 & 3.5 & 9.5 & 10.6 & 8.71 \\
\hline TUR (ARHAR) & 1.8 & 4.97 & 5.57 & 4.77 & 7 & 4.9 & 2.2 & 5.64 & 4.59 \\
\hline Total Food grains & 1.79 & 3.92 & 2.81 & 1.61 & 3 & 3.1 & 3 & 4.82 & 2.45 \\
\hline Coarse Cereals & 2.28 & 4.77 & 3.92 & 1.77 & 5 & 4.5 & 3.6 & 5.49 & 4.13 \\
\hline Total Pulses & 3.8 & 7.26 & 4.14 & 2.07 & 6 & 5.6 & 4.3 & 5.55 & 2.64 \\
\hline Total Oilseeds & 1.54 & 3.26 & 4.04 & 1.89 & 6 & 4.4 & 9.3 & 12.6 & 9.48 \\
\hline
\end{tabular}

Note: Authors calculations based on department of agriculture and cooperation (DAC) govt. of India data. 
Table 3 The Decomposition of production variability into its various components in India during 1950-5I to 1964-65

\begin{tabular}{|c|c|c|c|c|}
\hline Crops & Change in production & Area effect & Yield effect & Interaction effect \\
\hline Rice & $0.027(100.00)$ & $0.004(\mid 4.8 I)$ & $0.012(44.44)$ & $0.011(40.74)$ \\
\hline Wheat & $0.027(100.00)$ & $0.013(48.14)$ & $0.005(|8.5|)$ & $0.009(33.33)$ \\
\hline Jowar & $0.013(100.00)$ & $0.001(7.69)$ & $0.007(53.84)$ & $0.005(38.46)$ \\
\hline Bajra & $0.011(100.00)$ & $0.002(18.18)$ & $0.006(54.54)$ & $0.003(27.27)$ \\
\hline Maize & $0.055(100.00)$ & $0.011(20)$ & $0.017(30.9)$ & $0.027(49.09)$ \\
\hline Gram & $0.021(100.00)$ & $0.01(47.62)$ & $0.003(\mid 4.28)$ & $0.008(38.09)$ \\
\hline Groundnut & $0.031(100.00)$ & $0.025(80.64)$ & $0.002(6.45)$ & $0.004(12.90)$ \\
\hline Rapeseed \& Mustard & $0.023(100.00)$ & $0.015(65.21)$ & $0.003(\mid 3.04)$ & $0.005(21.74)$ \\
\hline Cotton & $0.027(100.00)$ & $0.006(22.22)$ & $0.009(33.33)$ & $0.012(44.44)$ \\
\hline Tobacco & $0.015(100.00)$ & $0.005(33.33)$ & $0.003(20.00)$ & $0.007(46.66)$ \\
\hline Sugarcane & $0.082(100.00)$ & $0.023(28.05)$ & $0.02(24.39)$ & $0.039(47.56)$ \\
\hline Jute \& Mesta & $0.042(100.00)$ & $0.032(76.19)$ & $0.003(7.14)$ & $0.007(16.66)$ \\
\hline TUR(ARHAR) & $0.004(100.00)$ & $0.001(25.00)$ & $0.007(175.00)$ & $(-) 0.004(100.00)$ \\
\hline Total Food grains & $0.016(100.00)$ & $0.003(18.75)$ & $0.006(37.5)$ & $0.007(43.75)$ \\
\hline Coarse Cereals & $0.009(100.00)$ & $0.001(11.11)$ & $0.004(44.44)$ & $0.004(44.44)$ \\
\hline Total Pulses & $0.009(100.00)$ & $0.005(55.55)$ & $0.002(22.22)$ & $0.002(22.22)$ \\
\hline Total Oilseeds & $0.019(100.00)$ & $0.011(57.89)$ & $0.003(\mid 5.78)$ & $0.005(26.3 \mathrm{I})$ \\
\hline
\end{tabular}

Note: Authors calculations based on department of agriculture and cooperation (DAC) govt. of India data.

Table 4 The decomposition of production variability into its various components in India during 1964-65 to 1987-88

\begin{tabular}{|c|c|c|c|c|}
\hline Crops & Change in production & Area effect & Yield effect & Interaction effect \\
\hline Rice & $0.035(100.00)$ & $0.002(5.7 I)$ & $0.02(57.6 \mathrm{I})$ & $0.013(37.14)$ \\
\hline Wheat & $0.17(100.00)$ & $0.034(20)$ & $0.054(31.76)$ & $0.082(48.23)$ \\
\hline Jowar & $0.016(100.00)$ & $0.003(18.75)$ & $0.023(143.75)$ & $(-) 0.01(62.5)$ \\
\hline Bajra & $0.016(100.00)$ & $0.003(18.75)$ & $0.016(100.00)$ & $(-) 0.003(18.75)$ \\
\hline Maize & $0.013(100.00)$ & $0.002(I 5.38)$ & $0.008(61.53)$ & $0.003(23.07)$ \\
\hline Gram & $0.006(100.00)$ & $0.003(50.00)$ & $0.005(83.33)$ & $(-) 0.002(33.33)$ \\
\hline Groundnut & $0.009(100.00)$ & $0.001(I 1.11)$ & $0.009(100.00)$ & $(-) 0.001(\mathrm{I} I . \mathrm{I} I)$ \\
\hline Rapeseed\& Mustard & $0.073(100.00)$ & $0.013(\mid 7.81)$ & $0.029(39.72)$ & $0.03 I(42.46)$ \\
\hline Cotton & $0.019(100.00)$ & $0.002(10.53)$ & $0.023(121.05)$ & $(-) 0.006(30.94)$ \\
\hline Tobacco & $0.02(100.00)$ & $0.004(20.00)$ & $0.019(95.00)$ & $(-) 0.002(|4.5|)$ \\
\hline Sugarcane & $0.036(100.00)$ & $0.009(25.00)$ & $0.01(27.77)$ & $0.017(47.22)$ \\
\hline Jute \& Mesta & $0.022(100.00)$ & $0.006(27.27)$ & $0.01 \mathrm{I}(50.49)$ & $0.005(22.72)$ \\
\hline TUR(ARHAR) & $0.022(100.00)$ & $0.009(40.91)$ & $0.005(22.72)$ & $0.008(36.36)$ \\
\hline Total Food grains & $0.037(100.00)$ & $0.002(5.4 I)$ & $0.027(72.97)$ & $0.008(21.62)$ \\
\hline Coarse Cereals & $0.005(100.00)$ & $0.003(60.00)$ & $0.013(260.00)$ & $(-) 0.01 \mathrm{I}(220.00)$ \\
\hline Total Pulses & $0.006(100.00)$ & $0.001(16.66)$ & $0.004(66.66)$ & $0.001(16.66)$ \\
\hline Total Oilseeds & $0.034(100.00)$ & $0.007(20.58)$ & $0.011(32.35)$ & $0.016(47.05)$ \\
\hline
\end{tabular}

Note: Authors calculations based on department of agriculture and cooperation (DAC) govt. of India data. 
Table 5 The decomposition of production variability into its various components in India during 1988-89 to 20I0-II

\begin{tabular}{lllll}
\hline Crops & Change in production & Area effect & Yield effect & Interaction effect \\
\hline Rice & $0.009(100.00)$ & $0.001(11.11)$ & $0.006(66.66)$ & $0.002(22.22)$ \\
Wheat & $0.019(100.00)$ & $0.004(21.05)$ & $0.006(31.57)$ & $0.009(47.36)$ \\
Jowar & $0.04(100.00)$ & $0.051(127.5)$ & $0.007(17.5)$ & $(-) 0.018(45)$ \\
Bajra & $0.019(100.00)$ & $0.003(15.78)$ & $0.029(152.63)$ & $(-) 0.013(68.42)$ \\
Maize & $0.063(100.00)$ & $0.014(22.22)$ & $0.02(31.74)$ & $0.029(46.03)$ \\
Gram & $0.018(100.00)$ & $0.007(38.88)$ & $0.004(22.22)$ & $0.007(38.88)$ \\
Groundnut & $0.011(100.00)$ & $0.018(153.83)$ & $0.008(68.37)$ & $(-) 0.014(121.79)$ \\
Rapeseed \& Mustard & $0.03(100.00)$ & $0.009(30.00)$ & $0.011(36.67)$ & $0.01(33.33)$ \\
Cotton & $0.111(100.00)$ & $0.011(9.91)$ & $0.07(63.06)$ & $0.029(26.12)$ \\
Tobacco & $0.021(100.00)$ & $0.011(52.38)$ & $0.007(33.33)$ & $0.005(23.80)$ \\
Sugarcane & $0.014(100.00)$ & $0.01(71.43)$ & $0.001(7.14)$ & $0.003(21.43)$ \\
Jute \& Mesta & $0.023(100.00)$ & $0.009(39.13)$ & $0.011(47.82)$ & $0.003(13.04)$ \\
TUR(ARHAR) & $0.003(100.00)$ & $0.0005(16.66)$ & $0.002(66.66)$ & $0.0005(16.66)$ \\
Total Food grains & $0.008(100.00)$ & $0.001(17.22)$ & $0.009(122.22)$ & $(-) 0.003(37.5)$ \\
Coarse Cereals & $0.005(100.00)$ & $0.01(200.00)$ & $0.02(400.00)$ & $(-) 0.025(500.00)$ \\
Total Pulses & $0.003(100.00)$ & $0.002(66.66)$ & $0.002(66.66)$ & $(-) 0.001(33.33)$ \\
Total Oilseeds & $0.028(100.00)$ & $0.007(25.00)$ & $0.009(32.14)$ & $0.012(42.85)$ \\
\hline
\end{tabular}

Note: Authors calculations based on department of agriculture and cooperation (DAC) govt. of India data.

\section{Conclusion}

To conclude, growth is a necessary condition for the success of agriculture sector in any region/districts. Low instability without growth is meaningless. In other words, instability can be used as a sufficient condition while assessing the performance of agriculture sector of any region. A moderate and significant growth in production accompanied by a low level of instability of any crop is desirable for sustainable development of agriculture in India as compared to high growth in production and high level of instability. There is an inevitable trend that arable land in India will decline over time due to urban development and industrialization. The area for crops has declined more sharply in recent years than in the past and will continue further in the future. The Indian government should concentrate on the supply of public goods such as land infrastructure, various land use experiments, and agricultural $\mathrm{R} \& \mathrm{D}$ (research and development) activities to the development of viable agriculture in the country. The need of the hour is to secure varietal improvement of minor crops to compete with major crops in terms of suitable revenue generations.

\section{Conflict of interest}

None.

\section{Acknowledgements}

The author declares no conflict of interest.

\section{References}

1. Cummings JW, Ralph, SK Ray. 1968-69 Food grain production: relative contribution of weather and new technology. Economic and Political Weekly. 1969;4(39):163-174.
2. Boyce, Jock K. Agrarian impasse in Bengal: International constraints to technological change. United States, New York, Oxford USA: University Press; 9187;1(3):397-399.

3. Das PS. Growth and Instability in crop output in Eastern India”. Economic and Political Weekly. 19789;13(41):1741-1748.

4. Deshpande RS, MV Nadkarni. Agricultural growth, instability in productivity and Rainfall: Case of Karnataka. Economic and Political Weekly. 1982;17(52):127-134.

5. Anderson Jock R, PBR Hazell. Variability in Grain yields: Implications for Agricultural Research and Policy in Developing Countries. International Food Policy Research Institute, The Johns Hopkins University Press, Baltimore and London; 1989.

6. Ray SK, Cummings RW, Herdt JRW. Agricultural prices, production and growth. Economic and Political Weekly. 1979;14(39):97-105.

7. Rao, Hanumantha CH, Ray SK, et al. Unstable agriculture and droughts: implication for policy. New Delhi, India: Vikas Publishing House Pvt. Ltd; 1998.

8. Brush SB. Reconsidering the green revolution: diversity and stability in cradle areas of crop domestification. Human Ecology. 1992;20(2):145167.

9. Hazell PBR. Instability in Indian Food grain production. International Food Policy Research Institute, Research Report. 1982;30:1-60.

10. Mehra S. Instability in Indian Agriculture in the context of the New Technology. International Food Policy Research Institute, Research Report; 1981. $25 \mathrm{p}$.

11. Cuddy JDA, PA Della Valle. Measuring the instability of time series data. Oxford Bulletin of Economics and Statistics. 1978;40(1):79-85.

12. Ghosh BK. Growth and variability in the production of crops in West Bengal agriculture. Trends in Agricultural Economics. 2010;3(3):135146. 
13. Anderson Jock R. Impacts of climate variability in Australian agriculture. Review of Marketing and Agricultural Economics. 1979;47(3):147-177.

14. Anderson, Jock R, Dillon, et al. changing variability in cereal production in Australia. Review of Marketing and Agricultural Economics. 1988;56(3):270-286.

15. Chand R, SS Raju. Instability in Andhra Pradesh agriculture- a disaggregate analysis. Agricultural Economics Research Review. 2008;21(2):283-288.

16. Donald W Larson, Eugene Jones, RS Pannu, et al. Instability in Indian agriculture-a challenge to the Green Revolution technology. Food Policy. 2004;29(3):257-273.

17. Dev SM. Growth and instability in food grains production:an inter-state analysis. Economic and Political Weekly. 1987;2(39):82-92.
18. Rosamond Naylor, Walter Falcon, Erika Zavaleta. Variability and Growth in Grain yields, 1950-94:Does the record point to greater variability, population and development review. Population Council. 1997;23(1):41-58.

19. Parthasarathy G. Growth rates and fluctuations of agricultural production: a district- wise analysis. Economic and Political Weekly. 1984;19(26):74-84.

20. Sawant SD, CV Achuthan. Agricultural growth across crops and regions: Emerging trends and patterns. Economic and Political Weekly. 1995;30(12):2-13.

21. Mohammad Pervez Wasim, Qazi Mohammad Tausif Akhtar, Amjad Ali, Shaukat Ali. Growth and instability in the major crops sector of east asian countries. Journal of Contemporary Asia. 2007;35(2):207-248. 